\title{
FAVAR (Factor-Augmented Vector Autoregression) Modeli Literatür Taraması
}

\section{Bige KÜÇÜKEFE ${ }^{1}$, Dündar Murat DEMİRÖZ ${ }^{2}$}

Favar (Factor-Augmented Vector Autoregression) Model Literature Review

ARTICLE INFO

Article History:

Date Submitted: 03.01.2017

Date Accepted: 30.03 .2017

JEL Classification:

$\mathrm{E} 12$

$\mathrm{E} 17$

C55

Keywords:

FAVAR

Monetary Policy

Transmission Mechanism

\begin{abstract}
In the Vector Autoregressive (VAR) models, which are widely used in economic studies and developed by Sims (1980), impulse response functions can only be obtained from variables included only because of the infrequent use of information sets, and the dimensions of structural shocks can not be measured precisely. It is also not possible that for some variables to be represented by a single time series. The VAR estimation is insufficient for parsing operations involving large data sets. FAVAR (Factor Augmented Vector Autoregression) method was developed by Bernanke, Boivin and Eliasz (2005) and this method can use large data sets. In this study, FAVAR method is tried to be explained by comparing with VAR, and a literature search is being conducted in this subject.
\end{abstract}

\footnotetext{
1Öğr. Gör. Dr., Namık Kemal Üniversitesi, Marmara Ereğlisi MYO, bkucukefe@nku.edu.tr ${ }^{2}$ Prof. Dr., İstanbul Üniversitesi, İktisat Fakültesi, İktisadi Gelişme ve Uluslararası İktisat ABD, dundar.demiroz@istanbul.edu.tr
} 


\section{Özet}

Ekonomik çalışmalarda yaygın biçimde kullanılan ve Sims (1980)'in literatüre kazandırdığı Vektör Otoregresyon (VAR) modellerinde, tüm bilgi setlerinin bir kısmının kullanımı nedeniyle, sadece dahil edilen değişkenler için etki tepki fonksiyonları elde edilebilir ve yapısal şokların boyutları tam olarak ölçülemez. Ayrıca bazı değişkenlerin tek bir zaman serisi ile temsil edilmeleri mümkün değildir. Bernanke, Boivin ve Eliasz (2005)'ın geliştirdiği FAVAR (Faktör Arttırımlı Vektör Otoregresyon) yöntemi büyük veri setlerini kullanabilmeye imkan tanımaktadır. Böylece FAVAR yöntemi büyük veri setlerinde etken olan makroekonomik faktörleri sistematik ve tutarlı biçimde tahmin edebilmektedir. $\mathrm{Bu}$ çalışmada FAVAR yöntemi VAR ile kıyaslanarak açıklanmış ve bu konuda bir literatür taraması yapılmıştır.

Anahtar Kelimeler: Favar, Para Politikası, Aktarım Mekanizması

\section{Giriş}

Bernanke, Boivin ve Eliasz (2005) tarafından geliştirilen FAVAR yöntemi, standart Vektör Otoregresyon (VAR)'a göre belirgin üstünlüklere sahiptir. Geweke (1977) tarafindan geliştirilen ve büyük boyutlu makroekonomik zaman serilerinin görece küçük sayıda tahmin 'faktörleri' ile özetlenebileceğini öngören Dinamik Faktör Modellerini (DFM) temel alan FAVAR yöntemi, büyük veri setlerinde etken olan makroekonomik faktörleri sistematik ve tutarlı biçimde tahmin edebilmektedir. $\mathrm{Bu}$ açıdan FAVAR yöntemi VAR analizindeki serbestlik derecesi probleminin doğal bir çözümü olmuştur (Bagzibagli, 2012). Çok fazla sayıda değişken için etki tepki fonksiyonları da FAVAR yöntemi ile elde edilebilmektedir. Ayrıca, bazı değişkenlerin tek bir zaman serisi ile temsil edilebilmeleri mümkün değildir. Örnek vermek gerekirse, "ekonomik faaliyet” kavramı sadece endüstriyel üretim veya gerçek GSMH ile gösterilemez. Bir politika değişiminin "ekonomik faaliyet” üzerinde neden olduğu etkileri değerlendirmek için, işsizlik ve satışlar gibi çoklu göstergenin verdiği tepkileri gözlemlemek gerekir. FAVAR ile bir zaman serisi ile temsil edilemeyen faktörler de modele dahil edilebilmektedir. FAVAR yöntemi günümüzde birçok ekonomik araştırmada yaygın biçimde kullanılmaktadır. 


\section{Literatür Taraması}

FAVAR modelinin önemli bir özelliği, ekonomik göstergelerin oluşturduğu çok büyük bir veri kümesini sistematik biçimde kullanarak, incelenmek istenen verileri etkileyen makro ekonomik etkenleri tahmin etmesidir. Politika şoklarının sonuçlarını tahmin etme konusunda bu modelin standart VAR yöntemlerine kıyasla avantajı, ABD Merkez Bankası ve piyasa katılımcıları tarafından zaten yaygın biçimde kullanılmakta olan çok büyük veri kümesinden yararlanmasıdır. Ayrıca, gözlemlenemeyen faktörler de modele dahil edilebilmektedir. FAVAR modeli pek çok ekonomik uygulamada kullanılmaktadır (Bai, Kunberg ve Lu, 2014).

Büyük veri setlerinin içerdiği bilginin görece az sayıda tahmin endeksi veya faktörü ile özetlenebilmesini sağlayan dinamik faktör modelleri, standart VAR analizine alternatif olarak ortaya çıkmışlardır. Örneğin Stock ve Watson (2002), tahmin yöntemi olarak büyük veri setlerinin içerdiği bilgiyi özetleyen bir dinamik faktör modeli geliştirmişlerdir. Bernanke ve Boivin (2003), tahmin faktörleri kullanımının ABD Merkez Bankası'nın politika reaksiyonu fonksiyonu tahminini geliştireceğini gösterdiler.

Lagana ve Mounford (2005), FAVAR yöntemiyle İngiltere'de faiz oranlarının belirleyicileri üzerinde çalışmıştır. Standart VAR analizlerine göre daha bütünsel sonuçlar elde edildiği vurgulanmıştır. Böylece konut fiyatları ve hisse senedi piyasası gibi bir çok veriler de analize dahil edilebilmiştir. Beklenmeyen faiz oranları artışlarının fiyat artışları ile sonuçlandığı ve fiyat bilmecesinin görülmediği araştırmanın bulgularındandır.

Mönch (2005), Avrupa Merkez Bankası için hazırladığı "Forecasting The Yield Curve In A Data-Rich Environment A No-Arbitrage Factor-Augmented Var Approach" isimli çalışmasında FAVAR modelini arbitraj olmadan uygulamıştır.

FAVAR tahmin yöntemini uygulayan Boivin, Giannoni ve Mihov (2007), ABD verisi için, fiyatların sektöre özgü şoklara hızlı, makroekonomik şoklara ise yavaş tepki verdiğini gösterdiler. 653 kalem makroekonomik, endüstriyel ve fiyat verisinden oluşan büyük bir veri seti kullanılarak elde edilen FAVAR modeli, FED faiz oranındaki değişimlerin ürün bazında fiyatları nasıl etkilediğini araştırmak için kullanıldı. 
Senbet (2007), hazırladığı doktora tezinde FAVAR yöntemi ile ABD, Kanada, İngiltere, Japonya ve Fransa makroekonomi verilerini kullanarak para politikasının etkisini, aktarım mekanizmasını ve tepkisini incelemiştir. Sonuç olarak tezin ilk bölümünde FAVAR'ın bütün ülkelerde fiyat bilmecesini giderdiğini, para politikasının ekonomik değişkenler üzerinde anlamlı etkileri olduğunu ve ABD para politikasının Kanada, İngiltere ve Japonya'yı etkilediğini bulmuştur. ABD para politikası aktarım mekanizmasını incelediği tezin ikinci bölümünde faiz oranları kanalına ek olarak kredi kanalının para politikasının aktarım kanallarından olup olmadığı araştırılmış ve kredi kanalının para politikasını aktardığı sonucuna ulaşılmıştır. Üçüncü bölümde ise bu dört ülke için para politikasının kapasite kullanım oranı, işsizlik oranı, döviz kurları, uzun dönem faiz oranları gibi birçok makroekonomik değişkeni etkilediği gözlemlenmiştir.

Silva (2008), para politikası ile konut piyasası arasındaki bağlantıyı incelemek için FAVAR modelinden yararlandı 1959-2001 yıllarını kapsayan aylık bazda 120 makroekonomik zaman serisi kullanarak elde edilen tahminler, konut inşaatı başlangıçları ile para politikası şokları arasında negatif bir ilişki olduğunu ortaya koydu. Benzer bir çalışmada Gupta, Jurgias ve Kabundi (2010), Güney Afrika için para politikasının reel konut fiyatları üzerindeki etkisini FAVAR yöntemi ile araştırdılar ve konut fiyatları enflasyonunun para politikası şoklarına negatif tepki verdiğini buldular. FAVAR yaklaşımı ile büyük boyutlu bilgi setlerini kullanımının mümkün olması sayesinde, küçük boyutlu modeller kullanılarak yapılan analizlerde gözlenen konut fiyatları bilmecesine dair bir kanıt bu çalışmada bulunmadı.

Gupta, Kabundi ve Ziramba (2009)'nın ABD'nin savunma harcamalarının GSMH's1 üzerindeki etkilerini yine FAVAR ile ölçtüğü çalışmasında, 116 değişkeni 1976 ile 2005 yılları arasındaki verileri kullanarak ölçmüştür. Sonuç olarak savunma harcamaları kısa dönemde büyümeye pozitif yönde katkı sağlamıştır. Ancak bu pozitif etki sadece 2 çeyrek için geçerlidir. Onuncu çeyrekten sonra bu etki negatif yani büyümeyi azaltıcı yönde gerçekleşir.

17 endüstrileşmiş ülke verisiyle uluslararası şokların yayılımını ve ampirik literatürdeki teoriye uymayan durumları FAVAR ile araştıran Mumtaz ve Surico (2009), buldukları sonuçları üç ana başlık altında toplamışlardır. Birincisi; İngiltere dışındaki 
ülkelerde kısa dönem faiz oranında beklenmeyen bir düşüşün, İngiltere ekonomisi üzerindeki dinamik etkilerini şu şekilde özetler: Reel ev fiyatları, enflasyon, yatırım, GSYH ve tüketim büyümesinin bir yıl sonunda; ücretlerin iki yıl sonunda; tüketici fiyatları endeksinde ve GSYH deflatöründeki enflasyonun üç yıl sonunda zirve değerine ulaştı. İkincisi; pozitif uluslararası arz şoku, İngiltere tüketim deflatörü bileşenlerinin dağılımını negatif etkiledi. İngiltere'de gerçekleşen bir para şokuna olan tepkilerde; döviz kuru ve likidite bilmecesi, ötelenen indirim ve fiyat anomalileri bulunduğuna dair çok az kanıt elde edildi.

Blaes (2009) Euro bölgesinde (FAVAR) yöntemini kullanarak; para politikasının aktarım mekanizmasını incelemek amacıyla, bir para politikası şoku uygulandığında ekonominin nasıl tepki verdiğini araştırdı. Elde edilen bulgular arasında uzun dönemde daraltıcı para politikasının teoride de öngörüldüğü gibi parasal büyümeyi azalttığını buldu. Ancak kısa dönemde faizlerin yükselmesiyle tahvillerin arttığını ve bu sebeple M3'ün de artış gösterebileceği sonucuna vardı.

Dufour ve Stevanovic' (2008), makroekonomik uygulamalarını FAVARMA modeli ile yapmıştır. Bu modelde VARMA analizini kullanılması sayesinde etkisinin arttığı sonucuna varmışlardır.

Bork (2009), ABD Merkez Bankasının belirlediği faiz oranlarının makroekonomik ve finansal etkilerini araştırmıştır. Bunun için 120 zaman serisi verisi araştırmada yer almıştır. Çalışmasında Bernanke'nin iki aşamalı ve Bayesyen tek aşamalı metotlarına alternatif olarak EM algoritmasını kullanmıştır. $\mathrm{Bu}$ algoritma en çok benzerlik (maximum likelihood) yöntemini kullanır. Çalışmanın sonucunda Bork; FAVAR analizlerinde daha az faktörlü, fakat uzun gecikme dönemlerinin daha etkili sonuçlar verdiğini görmüştür. Dört faktörün ve 13 gecikme döneminin ideal olduğunu söylemiştir.

Ahmadi ve Ritschl (2009), ABD’de iki Dünya Savaşı arasındaki dönemdeki büyük buhranda para politikasının rolünü araştırmıştır. Kullandıkları FAVAR modelinde Bayesyen yöntemi ve MCMC metodunu tercih etmişlerdir. 164 makroekonomik değişkeni kullanarak arz ve talep şokları uygulanmıştır. Bu şoklara tepkiler zayıftır. Ancak buhran derinleştikçe, verilen tepkinin de arttığı gözlenmiştir. Sonuç olarak para politikasının Büyük Buhran'da bir 
etkisi olsa da, Buhran'ın daha çok parasal olaylardan etkilendiğini söylemek için yeterli veri yoktur.

İtalya Merkez Bankası için hazırlanan "On The Interaction Between Market And Credit Risk: A Factor-Augmented Vector Autoregressive (FAVAR) Approach" isimli makale Fiori ve Iannotti (2010) tarafından hazırlanmıştır. Para politikası şoklarının piyasa ve kredi risklerine etkisini araştırmak için FAVAR kullanılmıştır. 1999-2006 dönemi için 99 makroekonomik ve finansal İtalya ekonomisi verileri kullanılmıştır. İtalyan makro-finansal dalgalanmaların hepsini etkileyen ortak risk kaynakları olduğu varsayımıyla para politikası şokları uygulanmıştır. Böylece finansal sektör ile reel sektör arasındaki bağ da gözlemlenebilmiştir. Toplam dalgalanmanı yüzde 55'i bu yöntemle açıklanmıştır.

Lagana ve Sgro (2011), ABD kişisel gelir vergisi oranındaki bir şokun ABD ve Kanada ekonomileri üzerindeki dinamik etkilerini tahmin etmek için bir FAVAR modelinden yararlandılar. Modelin ayırt edici özelliği, ihracat ve ithalatın endüstri bazında ayrıştırılmasıdır. Bu sayede, iki ülke arasında ülke içi ve uluslararası aktarım mekanizmaları hakkında ek bilgiler elde edildi. Sonuçlar, FAVAR yaklaşımı kullanılarak ABD kişisel gelir vergisi oranlarındaki hareketlerin, ABD ekonomisi üzerindeki etkileri ve Kanada ekonomisine aktarımı hakkında akla yatkın tahminler üretilebileceğini gösterdi.

Soares (2011), Portekiz Merkez Bankası için yaptığı çalışmada; para politikası şoklarının etkilerini, Euro Bölgesi için ve tek para politikası uygulanan dönemi ele alarak araştırmıştır. Uygulanan para politikası sonucunda, standart Var yöntemiyle elde edilemeyecek etki tepki fonksiyonları ile sonuçlar gözlemlenebilmiştir. Para politikalarının etkilerinin çıktıya etkisinin çok orta seviyede olduğu ve fiyat düzeyini ise çok daha az etkilediği görülmüştür.

Zuniga (2011), Meksika ve Brezilya üzerinde uyguladığı FAVAR modelinde uluslararası parasal aktarım mekanizmasını izlemiştir. ABD'de meydana gelen bir parasal şokun Meksika ve Brezilya gibi gelişmekte olan iki ülkeyi nasıl etkilediği incelenmiştir. Sonuç olarak ana aktarım kanalının faiz oranları olduğu, döviz kurunun etkisinin ise istatistiki olarak anlamlı olmadığı sonucuna varılmıştır. 
Fukawa (2012), bir FAVAR modeli ve teorik bir dinamik stokastik genel denge modeli geliştirerek, hükümet harcamalarının etkilerini inceledi ve Japonya ekonomisine ait 107 zaman serisi kullanılarak geliştirilen modele göre hükümet harcamalarında ve yatırımlarında bir artış, özel tüketim ve reel ücretlerde de artışa neden olacağını gösterdi.

Chua (2012) FAVAR modelini para politikası şoklarının etkilerini görmek için Malezya ekonomisine uygulamıştır. 2000:3 ile 2010:10 dönemindeki 78 adet zaman serisi verisi kullanılan modelde finansal ve reel değişkenlerin para politikası şoklarından negatif etkilendiği görülmüştür.

Han (2012) teorik çalışmasında FAVAR yapısal şoklarının belirlenmesinin, birçok değişkenin faktör yüklemeleri kısıtlara neden olabileceği ve çözüm yolları üzerinde durmuştur.

Munir ve Qayyum (2012), “Measuring The Effects Of Monetary Policy In Pakistan: A Factor Augmented Vector Autoregressive Approach” isimli makalelerinde para politikasının etkilerini Pakistan ekonomisi için araştırmıştır. 1992:01 ile 2010:12 dönemi için yapılan çalışmada 115 aylık makroekonomik değişken ile faiz oranlarının para politikasındaki etkinliği kanıtlanmıştır.

FAVAR modelini geliştirmeyi amaçlayan bir başka çalışma da $\mathrm{Ng}$ ve Stevanovic (2012)'in “Factor Augmented Autoregressive Distributed Lag Models"dir. Literatürde FADL olarak geçen model ile FAVAR arasındaki benzerlik ve farklılıklar makalede tartışılmaktadır. FADL modeli etki tepki fonksiyonlarını çok az kısıtlamayla elde etmeyi amaçlar. Etkisi az olan zayıf faktörleri $X_{t}$ zaman fonksiyonuna almamayı sadece güçlü etkileri olanları tutmayı hedefler. FAVAR'dan farklı olarak FADL yöntemi geniş veri setinin hepsini kullanmak yerine, Wold testi ile verileri seçmeyi tercih eder.

He, Leung ve Chong (2013), Çin'de uygulanan para politikasını analiz etmiştir. FAVAR sonuçlarına göre; Çin Merkez Bankası'nın gösterge faiz oranları, repo oranları ve piyasaların parasal tercihlerinin Çin ekonomisine etkisi çok azdır. Sadece piyasanın belirlediği 
döviz kurunun etkisi orta düzeydedir. Piyasanın belirlemediği Çin Merkez Bankası ölçümleri, örneğin toplam kredi ve para arzının büyüme oranları, reel ekonomi ve fiyat seviyesi üzerinde etkilidir. Bu sebeple yakın gelecekte de Çin Merkez Bankası piyasanın belirlediği döviz kuru yerine bu araçları para politikasında kullanmaya devam edecektir.

Ampirik makroekonomik modelleme için büyük veri setlerinin artan önemi ile Vasishtha ve Maier (2013), küresel gelişmelerin Kanada ekonomisini nasıl etkilediğini analiz etmek için bir FAVAR modeli kullandılar ve Kanada'nın öncelikle yurtdışı hareket ve emtia fiyatlarındaki şoklara açık olduğunu, diğer taraftan küresel faiz oranları ve enflasyon şoklarının etkisinin belirgin biçimde daha az olduğunu buldular.

Belke ve Rees (2014), global şokların dünya ekonomisi ve ulusal merkez bankaları ile hükümetleri için etkisini değerlendirmek ve finansal küreselleşmenin artan etkisini incelemek için FAVAR yöntemini kullandı. G7 ülkeleri ve Avrupa bölgesi için 1984-2007 yıllarını kapsayan ve merkez bankaları açısından, artan küreselleşmenin sebep olduğu ekonomik yapının analiz edildiği çalışmada, küresel likidite şoklarının dünya ekonomisini ve değişik ulusal ekonomilerini önemli oranda etkilediği ve gayrimenkul fiyatları ile GSMH kaynaklı genel şoklarının da küresel boyutta etkileri olduğunu gösterdi.

Fernald, Spiegel ve Swanson (2014), Çin ekonomisine ait çok geniş bir ekonomik gösterge seti kullanarak ve Çin ekonomik faaliyetlerini ve enflasyonunu örtük değişkenler olarak alıp bir FAVAR modeli oluşturdu ve Çin para politikasının, Çin ekonomisi üzerindeki etkilerini tahmin etti. Çin verisinin güvenilirliğine dair sıkıntılar, pek çok seri için yeterli verinin bulunmaması ve Çin ekonomisinin geçirdiği hızlı ve yapısal değişimler nedeniyle, FAVAR yaklaşımı bu tip bir analiz için çok uygundur. Çalışmanın sonuçlarına göre; banka zorunlu rezervlerinin arttırılması, ekonomik faaliyetleri ve enflasyonu azaltıcı yönde bir etki yapar. Ayrıca, beklentilerle uyumlu biçimde, Çin merkez bankası tarafindan belirlenen faiz oranları da ekonomik faaliyetler ve enflasyon üzerinde çok önemli bir etkiye sahiptir.

Huh, D. Kim, W J Kim ve Park (2014), Asya Kalkınma Bankası için hazırladıkları çalışmada Doğu Asya ve Pasifik Bölgesinin en büyük 10 ekonomisini ele aldıkları çalışmada FAVAR analizini farklı bir alanda kullanmışlardır. Seçilen ülkeler Endonezya, Malezya, 
Filipinler, Singapur, Tayland, Hong Kong, Çin, Japonya, Kore Cumhuriyeti, Tayvan'dır. ASEAN (Association of Southeast Asian Nations) ismi ile kurulan Güneydoğu Asya Uluslar Birliği; 1999 yılında Çin Halk Cumhuriyeti, Japonya ve Kore Cumhuriyeti'ni katarak etki alanını genişletti. $\mathrm{Bu}$ alanda para politikası ve ortak para biriminin kurulmasının etkileri araştırılmaktadır. $\mathrm{Bu}$ amaçla konjonktür dalgalanmalarının senkronizasyon seviyesi incelenmekte ve dünyadan ve bölgeden kaynaklana beş ortak şok belirlenerek incelenen ülkeler için bu şoklardan elde edilen tepkiler FAVAR yöntemi ile öngörülmeye çalışılmıştır.

Bekiros ve Paccagnini (2014), "Forecasting the US Economy with a FactorAugmented Vector Autoregressive DSGE model" isimli çalışmasında DSGE modelinde FAVAR yöntemini kullanmıştır. DSGE modeli yapısı itibariyle çok biçimlendirilmiştir ve doğrudan verilere uygulanır. Hibrit DSGE modelleri sayesinde çok daha karmaşık, gerçek dünyanın problemleri ile ilgilenirken daha çok veri kullanılabilmektedir. Çalışmanın sonucunda DSGE modeline göre; FAVAR-DSGE modelinin istatistiki olarak tahmin gücünün çok daha iyi olduğu ortaya konulmuştur. Bekiros ve Paccagnini (2014), bizim çalışma yöntemimize başka bir bakış açısı getirmiştir.

Mordi ve Adebayo (2014), Nijerya ekonomisi için yaptığı çalışmada, para politikasının fiyatlar üzerindeki etkilerini FAVAR yöntemiyle ölçmüşlerdir. Para politikası araçları olarak da faiz oranları ve döviz kuru şoklarını kullanarak tüketici fiyat endeksi üzerindeki değişmeleri araştırmışlardır. 84 makroekonomik değişkenin 54 çeyrek dönem için verilerinin kullanıldığ üzerinde çok daha etkili olduğu görülmüştür. Konut ve ulaşım sektörlerindeki fiyatların döviz kuruna çok bağlı olduğu çalışmanın bulguları arasındadır. Ayrıca diğer sektörler için de döviz kuru fiyatlar üzerinde çok etkili bir para politikası kanalıdır.

Banerjee, Marcellino ve Masten (2015), çalışmalarında faktör modellerinde VAR yerine Hata düzeltme (Error Correction) modelini kullanmıştır. Bu modelde Hata düzeltme, koentegrasyon ve dinamik faktör modellerini birleştirmişlerdir. 
Huber ve Fisher (2015), ABD konjonktür dalgalanmalarını ve para politikasını analiz etmek için FAVAR'da Markov Switching yöntemini kullanmıştır. Resesyon dönemlerinde para politikasının etkinliğinin artması çalışmanın bulguları arasındadır.

Melolinna (2015), Euro Bölgesi, İngiltere ve ABD'de enflasyon dinamiklerini etkileyen makroekonomik faktörleri incelemek için bir FAVAR modelinden yararlandı. Çalışmaya konu olan üç ekonomi için enflasyon dinamikleri arasındaki farkları dikkate alan ampirik bir yöntem ihtiyacı nedeniyle, FAVAR kullanılan araştırma sonuçlarına göre, enflasyonun alt bileşenlerinin makroekonomik şoklara verdikleri cevabın her üç ülke için de benzer olduğu bulundu.

Roşoiu (2015), "Monetary Policy and Factor-Augmented VAR Model” isimli çalışmasında geniş bir ampirik literatürün konusu olan para politikası aktarım mekanizmasının ölçümünü ele almıştır. Makroekonomik değişkenler üzerinde para politikasının etkilerini incelemek için çok kullanışlı bir model olan FAVAR yöntemi tercih edilmiştir. 2000-2013 yılları arasındaki 92 değişken ile yapılan araştırmada enflasyon oranı, işsizlik oranı ve para politikası faiz oranının bu değişkenler üzerindeki etkilerine bakılmıştır.

Kılıç ve Çankaya (2015), ABD ekonomisinde ekonomik aktivitenin tüketici güvenine olan etkilerini analiz etmişlerdir. Çalışmanın sonucunda ekonomik aktivitenin ve tüketici güveninin birbirine çok güçlü şekilde ilişkili olduğu görülmüştür. Lahura (2010), para politikası şoklarının etkilerini Peru için araştırmıştır. Bu amaçla yarı yapısal FAVAR modelini ortaya koyarak 1995-2003 dönemi için etki-tepki fonksiyonunu elde etmiştir.

Stock ve Watson (2016), "Factor Models and Structural Vector Autoregressions in Macroeconomics" isimli çalışmalarında Dinamik Faktör Modelleri için bir rehber hazırlamışlardır. Handbook of Macroeconomics kitabının bir bölümü olarak hazırlanan bu çalışmanın ana amacı, yapısal VAR ile yapısal Dinamik Faktör Modellerinin nasıl geliştirilebileceği üzerinedir. Ayrıca son 15 yılda yapısal Var modellerindeki gelişmeler de anlatılmıştır. 


\section{FAVAR Yöntemi}

Bernanke, Boivin ve Eliasz, (2005) FAVAR modelini makalelerinde şu şekilde açıklamaktadırlar:

Derecesi $\mathrm{p}$ olan indirgenmiş haldeki standard bir VAR modelini, şu şekilde ifade edebililir:

$$
y_{t}=v+A_{1} y_{t-1}+\cdots+A_{p} A_{t-p}+u_{t}
$$

Eşitlikte $y_{t}$ bağımlı değişkenler vektörü $(\mathrm{Kx} 1), v$ sabit terim vektörü $(\mathrm{Kx} 1), u_{t}$ bağımsız ve özdeşçe dağılmış hata terimi ve $A_{1} \ldots A_{p}$ ise katsayı matrisleridir $(\mathrm{KxK})$. Herhangi bir VAR(p) süreci takip eden VAR(1) formu şeklinde yazılabilir:

$$
Y_{t}=v+\boldsymbol{A} Y_{t-1}+U_{t}
$$

eşitlikteki terimler:

$$
\begin{gathered}
Y_{t}=\left[\begin{array}{c}
y_{t} \\
y_{t-1} \\
\vdots \\
y_{t-p+1}
\end{array}\right], \quad v=\left[\begin{array}{c}
v \\
0 \\
\vdots \\
0
\end{array}\right], \\
\boldsymbol{A}=\left[\begin{array}{ccccc}
A_{1} & A_{2} & \cdots & A_{p-1} & A_{p} \\
I_{K} & 0 & \cdots & 0 & 0 \\
\vdots & \vdots & \ddots & \vdots & \vdots \\
0 & 0 & \cdots & I_{K} & 0
\end{array}\right], \quad U_{t}=\left[\begin{array}{c}
u_{t} \\
0 \\
\vdots \\
0
\end{array}\right]
\end{gathered}
$$

Aşırı parametreleştirme probleminden ötürü geleneksel VAR modellerinde sınırlı sayıda bağımlı değişken kullanılabilir (küçük $\mathrm{K}$ değeri). FAVAR yöntemi kullanılarak bir VAR modeline çok sayıda bağımlı değişken dahil edilebilir.

FAVAR yöntemini açıklamak için ilk olarak gözlemlenebilir $M$ sayıda ekonomik değişkenden oluşan $Y_{t}$ vektörünün ekonomi üzerinde yaygın bir etkiye sahip olduğunu varsayalım. Bu aşamada amaç; değişkenler arasındaki yapısal ilişkiyi ortaya çıkarmak veya 
tahmin yapmak olabilir. Standart yöntemi takip edecek olursak, $Y_{t}^{\prime}$ 'yi kullanarak bir VAR, yapısal VAR (SVAR) veya başka çok değişkenli zaman serisi model tahmini ile devam edilebilir. Ancak, pek çok uygulamada $Y_{t}$ 'nin içinde yer almayan ve gözlemlenemeyen ama zaman serisini modellemek için önem taşıyan ek bir ekonomik bilgi olabilir. Bu ek bilgiyi $K$ sayıda gözlemlenemeyen faktörden oluşan $F_{t}$ ile temsil edebileceğimizi var sayalım. Örnek vermek gerekirse "Ekonomik faaliyet" veya "kredi koşulları" gözlemlenemeyen faktörlerdir. Bir veya iki seri ile kolayca temsil edemeyeceğimiz bu faktörler ekonominin genelini etkilerler.

Varsayalım ki $\left(F_{t}, Y_{t}\right)$ 'nin ortak dinamikleri şu şekilde ifade edilebilsin:

$$
\left[\begin{array}{l}
F_{t} \\
Y_{t}
\end{array}\right]=\Phi(L)\left[\begin{array}{l}
F_{t-1} \\
Y_{t-1}
\end{array}\right]+v_{t}
$$

Eşitlikte $\Phi(L), d$ sınırlı dereceden bir gecikme polinomudur ve yapısal VAR literatüründe olduğu gibi öncü kısıtlamalar içerebilir. $v_{t}$ ise ortalaması sıfır olan bağımsız ve özdeşçe dağıtılmış hata terimidir ve kovaryans matrisi $Q$ 'dur.

Eşitlik $(8),\left(F_{t}, Y_{t}\right)$ biçiminde bir VAR'dır. $Y_{t}^{\prime}$ 'yi $F_{t-1}$ 'e ilişsilendiren $\Phi(L)$ teriminin tamamının sıfır olması durumunda bu sistem standart bir VAR modeline indirgenir. Diğer durumda ( $Y_{t}$ 'yi $F_{t-1}$ 'e ilişkilendiren $\Phi(L)$ terimi sıfır değilse) eşitlik (3) bir FAVAR'dır. $\mathrm{Bu}$ nedenle mevcut VAR sonuçlarına direk bir eşleşme vardır ve (3), $F_{t}$ 'nin içerdiği ilave bilginin marjinal katkısını değerlendirmenin bir yoludur. Ayrıca, gerçek sistem bir FAVAR ise VAR katsayıları ve impuls cevabı katsayıları gibi değerler genellikle tahmin edilebilirler.

$F_{t}$ değişkenleri gözlenebilir olmadıkları için eşitlik (3) direk olarak tahmin edilemez. Ancak, çok sayıda ekonomik değişkeni potansiyel olarak etkileyen temsili faktörler yorumlanarak, bir grup ekonomi zaman serisi gözlemi kullanarak gerçek faktörler hakkında bazı sonuçlara varılabilir. Örnek olarak, varsayalım ki elimizde bir grup arka plan (bilgi amaçl1) zaman serisi olsun ve bu seriyi toplu biçimde $N \times 1$ vektörü $X_{t}$ ile gösterelim. $N$ tane bilgi amaçlı zaman serisi "büyük" bir seridir ve toplam faktör sayısından çok daha büyük olduğunu $(K+M \ll N)$ varsayalım. Bilgi amaçlı zaman serisi $X_{t}$ ile gözlemlenemeyen $F_{t}$ ve gözlenebilir $Y_{t}$ faktörleri arasında şu şekilde ilişkili olsun: 


$$
X_{t}^{\prime}=\Delta^{f} F_{t}^{\prime}+\Delta^{y} Y_{t}^{\prime}+e_{t}^{\prime}
$$

Eşitlikte, $\Delta^{f}$ bir $N$ x $K$ yükleme faktörü matrisi, $\Delta^{y}$ bir $N$ x $M$ matrisi ve $e_{t}$ ise ortalama değeri sıfır olan $N$ x 1 hata terimleri vektörüdür $\left(\mathrm{E}\left(e_{t} e_{t}{ }^{\prime}\right)=R\right)$. Hata vektörü $e_{t}$, tahminin hangi yönteme (esas bileşenler veya olasılık yöntemi) göre yapıldığına bağlı olarak zayıf ilişkili veya bağımsız olabilir. Eşitlik (3)'nin dayandığı fikir, genellikle birbiriyle ilişkili olan $F_{t}$ ve $Y_{t}$ 'nin, $X_{t}$ 'yi dinamik olarak tanımlayan kuvvetleri temsil ettiğidir. Bu fikirden hareketle, $Y_{t}$ koşuluna bağlı olarak $X_{t}$, gözlemlenemeyen $F_{t}$ faktörlerinin gürültü içeren ölçümleridir. Eşitlik (4)'den çıkarılabilecek $X_{t}$ 'nin sadece şimdiki faktör ve zaman gecikmeli olmayan değerlerine bağlı olduğu değerlendirmesi uygulamada kısıtlayıcı değildir. Çünkü, $F_{t}$ temel faktörlerin rasgele zaman gecikmeli değerleri olarak yorumlanabilir.

(3) ve (4) eşitliklerinin tahmini iki farklı yaklaşım ile yapılabilir. Birincisi, $C^{\prime}{ }_{t}=$ $\left(F_{t}^{\prime}, Y_{t}^{\prime}\right)$ ortak bileşenleri tarafından kapsanan alanı gösteren ve parametrik olmayan bir yol sunan iki-aşamalı temel bileşenler yöntemidir. İkinci yol ise tek-aşamalı Bayesyen olasılık yaklaşımıdır. Bu çalışmada iki-aşamalı ortak bileşenler yöntemi kullanılmıştır.

Birinci adımda $C_{t}$ ortak bileşenleri, $X_{t}$ 'nin ilk $K+M$ temel bileşenleri kullanılarak tahmin edilir ve bu yapılırken $Y_{t}$ gözlenebilir olmasından istifade edilmez. Ancak, Stock ve Watson (2002) tarafindan gösterildiği gibi, eğer $N$ yeterince büyük ve kullanılan temel bileşenlerin sayısı en az faktörlerin gerçek sayısı kadar büyük ise temel bileşenler tutarlı biçimde $F_{t}$ ve $Y_{t}$ tarafından kapsanan alanı ortaya çıkarır. $Y_{t}$ 'nin kapsamadığı $\widehat{C}_{t}$ tarafından kapsanan alan $\widehat{F}_{t}$ elde edilir. İkinci adımda ise, (3)'deki FAVAR eşitliği $F_{t}$ yerine $\widehat{F_{t}}$ konularak standart yöntemler ile tahmin edilir.

FAVAR yönteminin önemli avantajlarından biri olan etki tepki fonksiyonlarını elde etmek için ilk olarak eşitlik (3) hareketli ortalamalar (MA) olarak ifade edilir (Blaes, 2009):

$$
\left[\begin{array}{l}
\hat{F}_{t} \\
Y_{t}
\end{array}\right]=\Psi(L) v_{t}
$$

ve $\hat{F}_{t}$ ve $Y_{t}$ için etki tepki fonksiyonları elde edilir. Eşitlikte $\Psi(L)=\left[I-\phi_{1} L-\cdots-\right.$ $\left.\phi_{d} L^{d}\right]^{-1}=[I-\Phi(L)]^{-1}$. Sonrasında eşitlikler (2) ve (3) kullanılarak, 


$$
X_{i t}^{I R F}=\left[\begin{array}{ll}
\widehat{\Lambda}^{f} & \widehat{\Lambda}^{y}
\end{array}\right]\left[\begin{array}{l}
\hat{F}_{t} \\
Y_{t}
\end{array}\right]=\left[\begin{array}{ll}
\hat{\Lambda}^{f} & \hat{\Lambda}^{y}
\end{array}\right] \Psi(L) v_{t}
$$

eşitliği yazılır ve $X_{t}$ 'de yeralan herhangi bir değişken için etki tepki fonksiyonu bulunur.

Hesaplaması kolay olan iki-aşamalı yaklaşımın dezavantajı ikinci adımda ortaya çıkan Regresör'lerdir. Elde edilen etki-tepki fonksiyonları için hassas güven aralıklarını sağlamak için faktör tahminindeki belirsizliği hesaba katan ve Kilian (1998) baz alınarak geliştirilen bir "bootstrap" prosedürü kullanıld1.

Etki tepki fonksiyonlarında güven aralıklarının hesaplanması için Runkle (1987) tarafından önerilen standart bootstrap tekniğinin dayandığı yaklaşım, şokların Gauss dağılımı olduğunu varsaymadan etki tepki fonksiyonları için küçük örnek dağılım tahminlerinin elde edilmesine dayanır. Kilian (1998), geliştirdiği “bootstrap sonrası bootstap” algoritması ile etki tepki fonksiyonlarında var olan sapmanın (bias) düzeltilebileceğini kanıtlamıştır. $A(L) y_{t}=e_{t}$ formunda $p$ dereceden bir model için "bootstrap sonrası bootstrap" prosedürü şu adımları içerir.

1. $\quad$ EKK (En küçük kareler) yöntemi ile $\hat{A}(L), \hat{\Sigma}$, ve $\hat{e}_{t}$ tahmin edilir.

2. $\hat{A}(L)$ için bir sapma düzeltme hesaplanır:

a. $\quad b=1 . . B$ için, $\hat{e}_{t}{ }^{\prime} \operatorname{den} e_{t, b}^{*}$ seçilir, $y_{t, b}^{*}=\hat{A}(L) e_{t, b}^{*}$ oluşturulur.

b. $\quad y_{t, b}^{*}$ üzerinden EKK ile $\hat{A}_{b}^{*}(L)$ tahmin edilir.

c. $\quad \widehat{\Psi}=\frac{1}{B} \sum_{b=1}^{B} \hat{A}_{b}^{*}(L)-\hat{A}(L)$ sapması tahmin edilir.

3. Sapma düzeltesi yapılarak $\tilde{A}(L)$ oluşturulur. Eğer $\hat{A}(L) y_{t}$ durağan ise durağanlık korunmalıdır.

a. Ĕger $\hat{A}(z)$ determinant köklerinden biri birim çemberin içindeyse (durağan değil), $\tilde{A}(L)=\hat{A}(L)$ alınır.

b. Eğer $\hat{A}(z)$ determinant köklerinin tamamı birim çemberin dışındaysa (durağan), $\tilde{A}(L)=\hat{A}(L)-\widehat{\Psi}(1-\delta)^{j}$ alınır $(j: \tilde{A}(L)$ determinant köklerini birim çemberin dışında olmasını sağlayan en küçük negatif olmayan tam sayı).

4. $\quad \tilde{A}(L)$ ve $\theta(\tilde{A}(L), \widehat{\Sigma})$ bootstrap yapilır: 
a. $\quad b=1 . . B$ için, $e_{t, b}^{*}$ 'den $\tilde{e}_{t}$ seçilir, $y_{t, b}^{*}=\tilde{A}(L)^{-1} e_{t, b}^{*}$ oluşturulur.

b. $\quad \hat{\tilde{A}}_{b}^{*}(L)$ ve $\Sigma_{b}^{*}$ tahmin edilir.

c. Yukarıdaki şekilde sapma düzeltmesi yapılarak $\hat{\tilde{A}}_{b}^{*}$ bulunur. Bunun sonucunda bir bootstrap içinde başka bir bootstap elde edilir.

d. $\quad \theta_{b}^{*}\left(\hat{\tilde{A}}_{b}^{*}, \Sigma_{b}^{*}\right)$ hesaplanir.

e. $\quad \theta_{b}^{*}\left(\hat{\tilde{A}}_{b}^{*}, \Sigma_{b}^{*}\right)$ sıklık derecesi (quantiles) kullanılarak güven aralıkları bulunur.

\subsection{FAVAR Yöntemine Örnek Bir Uygulama}

Merkez bankaları politikalarını belirlerken rutin olarak çok sayıda ekonomik değişkeni takip ederler. FAVAR yöntemine uygulama örneği olarak merkez bankalarının ve araştırmacıların niçin fazla sayıda değişkeni göz önüne almaları gerektiğini ortaya koyan standart bir makroekonomik çerçeve kullanıldı (Bernanke, Boivin ve Eliasz, 2005).

Ekonominin dinamiklerinin az sayıda makroekonomik etken tarafından belirlendiği basit bir geriye dönük modeli ele alalım.

$$
\begin{gathered}
\pi_{t}=\delta \pi_{t-1}+\kappa\left(y_{t-1}-y_{t-1}^{n}\right)+s_{t} \\
y_{t}=\phi y_{t-1}-\psi\left(R_{t-1}-\pi_{t-1}\right)+d_{t} \\
y_{t}^{n}=\rho y_{t-1}^{n}+\eta_{t} \\
s_{t}=\alpha s_{t-1}+v_{t}
\end{gathered}
$$

Eşitlik (7) toplam arz veya Phillips eğrisi denklemidir ve enflasyonu $\left(\pi_{t}\right)$ gecikmeli enflasyon değeri $\left(\pi_{t-1}\right)$, fiili çıktı ile potansiyel çıktı arasındaki fark $\left(y_{t-1}-y_{t-1}^{n}\right)$ ve maliyet artış şoku $\left(s_{t}\right)$ ile ilişkilendirir. Eşitlik (8)'te toplam talep $\left(y_{t}\right)$ veya IS eğrisi gecikmeli çıktı; gecikmeli reel faiz oranı $\left(R_{t-1}-\pi_{t-1}\right)$ ve bir talep şoku $\left(d_{t}\right)$ ile ifade edilmektedir. Eşitlik (9) ve (10)'te ise potansiyel çıktı $\left(y_{t}^{n}\right)$ ve maliyet artış şoku $\left(s_{t}\right)$ birinci dereceden otoregresif süreçler şeklinde gösterilmiştir. Ayrıca, nominal faiz oranının $\left(R_{t}\right)$ merkez bankası tarafından basit bir Taylor kuralı ile belirlendiği varsayıldı.

$$
R_{t}=\beta \pi_{t}+\left(y_{t}-y_{t}^{n}\right)+\varepsilon_{t}
$$

Eşitlikte merkez bankası mevcut enflasyona ve çıktı farkına cevap vermektedir. Politika şokları $\left(\varepsilon_{t}\right)$ normal dağılım $(N(0,1))$ olduğu varsayıldı. Aynı zamanda modelin 
ekonomideki konjonktür dalgalanma dinamiklerini yansıttığı kabul edildi. Gözlenebilir çok sayıdaki $(N)$ makroekonomik göstergenin $\left(X_{t}\right)$ takip eden şekilde bağlantılı olduğunu varsayalım:

$$
X_{t}=\Lambda\left(\begin{array}{lllll}
y_{t}^{n} & s_{t} & \pi_{t} & y_{t} & R_{t}
\end{array}\right)^{\prime}+\varepsilon_{t}
$$

Modeli oluşturan eşitlikler (7 - 12) vektör otoregresif (VAR) formda yazılabilir. Ancak modelin standart bir VAR veya bir FAVAR ile doğru biçimde tanımlanabilmesi tamamen varsayılan bilgi yapısına bağlıdır. İlk olarak eşitlik (11) değişkenlerin t-1 veya daha öncesi değerleri kullanılarak yeniden yazılırsa model, eşitlik (3)'in kısıtlı hali olarak ifade edilebilir. Bu durumda,

$$
\begin{gathered}
\Phi(L)=\Phi=\left[\begin{array}{ccccc}
\rho & 0 & 0 & 0 & 0 \\
0 & \alpha & 0 & 0 & 0 \\
0 & \alpha & \delta & \kappa & -\kappa \\
0 & 0 & \psi & \Phi & -\psi \\
-\gamma \psi & \beta \alpha & (\beta \delta+\gamma \psi) & \beta \kappa+\gamma \Phi & -(\beta \kappa+\gamma \rho)
\end{array}\right] \\
v_{t} \equiv\left[\begin{array}{cccc}
0 & 0 & 1 & 0 \\
0 & 0 & 0 & 1 \\
0 & 0 & 0 & 1 \\
1 & 0 & 0 & 0 \\
\gamma & 1 & -\gamma & \beta
\end{array}\right]\left[\begin{array}{c}
d_{t} \\
\varepsilon_{t} \\
\eta_{t} \\
v_{t}
\end{array}\right]
\end{gathered}
$$

ve

$$
\left[\begin{array}{l}
F^{\prime} \\
Y^{\prime}
\end{array}\right]=\left[\begin{array}{lllll}
y_{t}^{n} & s_{t} & \pi_{t} & y_{t} & R_{t}
\end{array}\right]^{\prime}
$$

olarak yazılabilir. Değişkenler, direkt olarak gözlemlenebilir olup olmadıklarına göre $F_{t}$ ve $Y_{t}$ arasinda ayrilırlar.

Eğer modeldeki bütün değişkenlerin merkez bankası tarafindan gözlemlenebilen ampirik ölçümlere tam olarak karşılık geldiği varsayılırsa, $Y_{t}^{\prime}=\left[\begin{array}{lllll}y_{t}^{n} & s_{t} & \pi_{t} & y_{t} & R_{t}\end{array}\right]^{\prime}$ ve $F^{\prime}{ }_{t}=\emptyset$ olur. Bu durumda eşitlik (12)'ye gerek kalmaz ve model $Y_{t}$ içinde kısıtlı bir VAR'a indirgenir ve klasik VAR yöntemleri kullanılarak tahmin edilir. Örnek olarak, politika şoklarının $\left(\varepsilon_{t}\right)$ ekonomi üzerindeki dinamik etkilerini ve etki-tepki fonksiyonlarını kısıtlı veya kısıtlı olmayan VAR yöntemi kullanılarak elde eden pek çok çalışma yapılmıştır. 
Ancak, $Y_{t}$ 'nin bütün bileşenlerinin merkez tarafindan gözlemlenebilir olduğu gerçekçi olmayan bir varsayımdır. Bu nedenle, standart VAR'a kıyasla FAVAR daha gerçekçi bir yaklaşımdır. Modelde merkez bankasının potansiyel çıktıyı ve maliyet artış şoklarını direk olarak gözlemleyemeyediği durum için FAVAR yapısı $F^{\prime}{ }_{t}=\left[\begin{array}{ll}y_{t}^{n} & s_{t}\end{array}\right]^{\prime}$ ve $Y^{\prime}{ }_{t}=$ $\left[\begin{array}{lll}\pi_{t} & y_{t} & R_{t}\end{array}\right]^{\prime}$ şeklinde olur. Diğer taraftan, farklı bir yaklaşım olarak, çıktı $\left(y_{t}\right)$ ve enflasyonun $\left(\pi_{t}\right)$ direkt olarak gözlemlenemediği iddia edilebilir. Makroekonomik veriler birkaç kere düzeltilmiş olabilir ve bir ölçüm hatası her zaman mevcuttur. Ayrıca, teorik kavramlar her zaman mevcut veri ile birebir eşleşmeyebilir. Örnek olarak, teorik modeldeki “çıktı", bir konjonktür dalgalanmaları analizinde reel GSYH verisinden ziyade ekonomik faaliyetlerin görünür değerine karşılık gelebilir. Benzer şekilde, enflasyon oranının gerçek olarak ölçülmesi mümkün olmayabilir (Bills, 2004). Çıktı ve enflasyon oranının da direkt olarak ölçülemediği kabul edilirse, modelde yer alan merkez bankası sadece nominal faiz oranı (politika enstrümanı) ile gürültülü geniş bir makroekonomik veri setini gözlemleyebilir. Bu durumda eşitlik (12), şu şekilde yazılabilir: $F^{\prime}{ }_{t}=\left[\begin{array}{llll}\pi_{t} & y_{t} & y_{t-1}^{n} & s_{t}\end{array}\right]^{\prime}$ ve $Y^{\prime}{ }_{t}=\left[\begin{array}{ll}R_{t}\end{array}\right]^{\prime}$. Bu bilgi yapısı altında merkez bankası para polikasını belirlemek için, $X_{t}$ veri setinde yer alan bilgiyi kullanması gerekir. Bu süreç FAVAR yapısı ile modellenebilir.

\section{Sonuç}

Her ne kadar Vektör Otoregresyon (VAR) modelleri yaygın biçimde ekonomik çalışmalarda kullanılsa da, bazı değişkenlerin tek bir zaman serisi ile temsil edilebilmeleri mümkün değildir. Örnek vermek gerekirse, "ekonomik faaliyet” kavramı sadece endüstriyel üretim veya gerçek GSMH ile gösterilemez. Bir politika değişiminin "ekonomik faaliyet” üzerinde neden olduğu etkileri değerlendirmek için, işsizlik ve satışlar gibi çoklu göstergenin verdiği tepkileri gözlemlemek gerekir. Alan FAVAR yöntemi, büyük veri setlerinde etken olan makroekonomik faktörleri sistematik ve tutarlı biçimde tahmin edebilmektedir. Ayrıca, çok fazla sayıda değişken için etki tepki fonksiyonları da FAVAR yöntemi ile elde edilebilmekte ve tek bir zaman serisi ile temsil edilemeyen (ekonomik faaliyet gibi) faktörler de modele dahil edilebilmektedir. FAVAR yöntemi günümüzde bir çok ekonomik araştırmada yaygın biçimde kullanılmaktadır. 


\section{Kaynakça}

Ahmadi, A.P. \& Ritschl, A. (2009), "Depression Econometrics: A FAVAR Model Of Monetary Policy During The Great Depression", Economic History Working Papers, No. $130 / 09$

Ba1, J. Kunpeng, Li. \& Lu, L. (2014), "Estimation And Inference Of FAVAR Models”, Mpra Paper No. 60960, Online: Http://Mpra.Ub.Uni-Muenchen.De/60960/

Bagzibagli, K. (2012), “Monetary Transmission Mechanism And Time Variation In The Euro Area", Department Of Economics Discussion Paper, 12-12. University Of Birmingham

Belke, A. \& Rees, A. (2014), "Globalization And Monetary Policy - A FAVAR Analysis For The G7 And The Eurozone", The North American Journal Of Economics And Finance, 29, 306-321.

Banerjee, A., Marcellino, M. \& Masten, I. (2015), “An Overview Of The FactorAugmented Error-Correction Model", University Of Birmingham Department Of Economics Discussion Paper, 15(3).

Bernanke, B. \& Boivin, J. (2003), "Monetary Policy In A Data-Rich Environment", Journal Of Monetary Economics, 50(3), 525-546.

Bernanke, B., Boivin, J. \& Eliasz, P. (2005), “Measuring The Effects Of Monetary Policy: A Factor-Augmented Vector Autoregressive (FAVAR) Approach.”, Quarterly Journal Of Economics, 120(1), 387-422.

Blaes, B. (2009), "Money And Monetary Policy Transmission in The Euro Area Evidence From Favar And Var Approaches", Discussion Paper, Dt. Bundesbank Frankfurt.

Boivin, J. Giannoni, M. \& Mihov, I. (2007), "Sticky Prices And Monetary Policy: Evidence From Disaggregated U.S. Data”, Nber Working Paper, 12824 
Bork, L. (2009), “Estimating Us Monetary Policy Shocks Using A Factor-Augmented Vector Autoregression: An Em Algorithm Approach", University Of Aarhus, Finance Research Group Working Paper F-2009-03.

Chua, S. Y. (2012), “Assessing The Effects Of Monetary Policy Shocks In Malaysia: A Factor Augmented Vector Autoregressive Approach”, Iup Journal Of Applied Economics, 11(3), 65-83.

Fernald, J.G., Spiegel, M.M. \& Swanson, E.T. (2014), “Monetary Policy Effectiveness in China: Evidence From A FAVAR Model”, Journal Of International Money And Finance, 49(A), 83-103

Fiori, R. \& Iannotti, S. (2010), “On The Interaction Between Market And Credit Risk: A Factor-Augmented Vector Autoregressive (FAVAR) Approach”, Banca D'italia Working Papers, 779.

Fukawa, K. (2012), "Estimation Of An Empirical FAVAR Model And DSGE Model For Evaluating Effects Of Government Spending In Japan”, PhD Thesis, City University Of New York.

Geweke, J. (1977), The Dynamic Factor Analysis Of Economic Time Series Models, Madison: Social System Research Institute,

Gupta, R. Jurgias, M. \& Kabundi, A. (2010), “The Effect Of Monetary Policy On Real House Price Growth In South Africa: A Factor-Augmented Vector Autoregression (FAVAR) Approach", Economic Modelling, 27(1), 315-323.

Gupta, R. Kabundi, A. \& Ziramba, E. (2009), “The Effect Of Defense Spending On Us Output: A Factor-Augmented Vector Autoregression (FAVAR) Approach", Defence And Peace Economics, 21(2),

He, Q. Leung, P. \& Chong, T.T. (2013), "Factor-Augmented Var Analysis Of The Monetary Policy In China”, China Economic Review, 25, 88-104. 
Huber, F. \& Fisher, M.M. (2015), “A Markov Switching Factor-Augmented Var Model For Analyzing Us Business Cycles And Monetary Policy", Vienna University Of Economics And Business Working Papers, No.201.

Huh, H-S. Kim, D., Kim, W. J. \& Park, C-Y. (2014), “A Factor-Augmented Vector Autoregression Analysis Of Business Cycle Synchronization in East Asia And Implications For A Regional Currency Union”, Adb Economics Working Paper Series, Asian Development Bank, No. 385

Kılıç, E. \& Cankaya, S. (2015), "Consumer Confidence And Economic Activity: A Factor Augmented Var Approach”, Journal Of Applied Economics, 48,

Lagana, G. \& Mountfront, A. (2005), "Measuring Monetary Policy in The Uk: A Factor-Augmented Vector Autoregression Approach", Manchester School, 73(1):77-78.

Lagana, G. \& Sgro, P.M. (2011), “A Factor-Augmented Var Approach: The Efffect Of A Rise in The Us Personal Income Tax Rate On The Us And Canada", Economic Modelling, 28(3), 1163-1169.

Lahura, E. (2010), “The Effects Of Monetary Policy Shocks In Peru: Semi-Structural Identification Using A Factor-Augmented Vector Autoregressive Model", Central Bank Of Peru Working Paper Series,

Mordi, N.O. \& Adebayo, M., A. (2009), “The Effect Of Monetary Policy On Prices in Nigeria: A Factor Augmented Vector Autoregressive (Favar) Modelling Approach", Csae Conference 2014: Economic Development in Africa, St Catherine's Collage, London: University Of Oxford

Mönch, E. (2005), "Forecasting The Yield Curve In A Data-Rich Environment A NoArbitrage Factor-Augmented Var Approach”, European Central Bank Working Paper Series No. 544

Mumtaz, H. \& Surico, P. (2009), “The Transmission Of International Shocks: A Factor Augmented Var Approach", Journal Of Money, Credit And Banking, 41(1), 
Munir, K. \& Qayyum, A. (2012), "Measuring The Effects Of Monetary Policy in Pakistan: A Factor Augmented Vector Autoregressive Approach”, Mpra Paper No. 35976.

Ng, S. \& Stevanovic, D. (2012), "Factor Augmented Autoregressive Distributed Lag Models", Çevrimiçi Https://Www.Aeaweb.Org/Conference/2013/Retrieve.Php?Pdfid=136, 10.07.2016.

Roşoiu, A. (2015), “Monetary Policy And Factor-Augmented Var Model”, Procedia Economics And Finance, 32, 400-407

Senbet, D. L. (2007), "Estimating The Impact, Transmission Mechanism And Reaction Function Of Monetary Policy: A Factor -Augmented Vector Autoregressive (FAVAR) Approach", PhD Thesis, Western Michigan University,

Silva, C.V. (2008), "The Effect Of Monetary Policy On Housing: A FactorAugmented Vector Autoregression (FAVAR) Approach", Applied Economics Letters, 15(10), 749-752.

Sims, C. A. (1980), “Macroeconomics And Reality”, Econometrica, 48, 1-48.

Stock, J.H. \& Watson, M.W. (2016), "Factor Models And Structural Vector Autoregressions in Macroeconomics", Handbook Of Macroeconomics, Çevrimiçi: Https://Www.Princeton.Edu/ Mwatson/Papers/Stock_Watson_Dfm_Hom_030916.Pdf, 10.08.2016.

Soares, R. (2011), “Assesing Monetary Policy in The Euro Area: A Factor-Augmented Var Approach”, Banco De Portugal Working Papers,

Vasishtha, G. \& Maier, P. (2013), “The İmpact Of The Global Business Cycle On Small Open Economies: A Favar Approach For Canada", The North American Journal Of Economics And Finance, 24, 191-207. 
Zuniga, Mc. (2011), “International Monetary Transmission, A Factor-Augmented Vector Autoregressive (FAVAR) Approach: The Cases Of Mexico And Brazil” Business And Economics Journal, 